\title{
ARABISASI KATA-KATA ASING SEBAGAI USAHA MEMPERTAHANKAN GRAMATIKA DAN MORFOLOGI BAHASA ARAB
}

\author{
Anida Yuspa \\ Sekolah Tinggi Ilmu Tarbiyah Darul Hijrah Martapura Kalimantan Selatan \\ yusfa345@gmail.com
}

\begin{abstract}
Abstrac
Interaction between nations in the world causes inter-language struggles that can cause positive or negative effects on one another. So there is a language that is very dominating other languages, and some eventually die without any speakers, or are forced to adopt some of the words or grammar of other languages.

There are three groups of expert opinions on the arabization of foreign words: the conservative, the pragmatic, and the moderate. The opinions of moderate groups are more representative of all the aspirations of Arabic experts.
\end{abstract}

Keyword: Arabization, Grammar, Arabic

\begin{abstract}
Abstrak
Interaksi antar bangsa di dunia menyebabkan adanya pergumulan antar bahasa yang dapat menyebabkan pengaruh positif ataupun negatif satu sama lain. Sehingga ada bahasa yang sangat mendominasi bahasa-bahasa yang lain, dan ada yang akhirnya mati tanpa ada penuturnya lagi, atau terpaksa harus mengadopsi sebagian dari kata atau gramatika dari bahasa lain.

Ada tiga kelompok pendapat pakar tentang arabisasi kata-kata asing: yaitu kelompok konservatif, kelompok pragmatis, dan kelompok moderat. Pendapat kelompok moderat lebih mewakili semua aspirasi para pakar bahasa Arab.
\end{abstract}

Kata Kunci: Arabisasi, Gramatika, Bahasa Arab

\section{Pendahuluan}

\section{Definisi Arabisasi Kata-Kata Asing}

Arabisasi kata-kata asing dalam istilah Arab dikenal dengan al-ta'rib, secara etimologis, al-ta'rib telah terdefinisikan sebagai proses penyerapan bahasa asing ke dalam bahasa Arab. Sedangkan, kata serapan hasil proses al- ta'rib disebut al-mu'arrab. Namun, dalam beberapa kasus, Al-Ta'rib memiliki kesamaan makna dengan al-I'rab berdasarkan beberapa bukti penggunaan keduanya oleh sebagian kecil linguis Arab klasik, seperti al-Jawhary saat menerangkan عرب: (dalam kamus al-Shihhaah عرب entri dan Abu Hatim dalam 
kamus al-Tahdzib ( ) إن جدة أصلها (أعجمي...فأعرب). Bahkan, Sibawaih dalam hal ini hanya menggunakan istilah al$i$ 'raab berikut derivasinya. ${ }^{1}$

Adapun al-ta'rib menurut terminologi, al-Jawaliqy mendefiniskan al-Mu'arrab sebagai kata serapan yang terdapat di dalam Al-Qur'an, Hadits, Atsar, syair, dan natsr klasik. ${ }^{2}$ Definisi ini memberikan pengertian bahwa al$m u$ 'arrab merupakan hasil proses penyerapan bahasa asing ke dalam bahasa Arab yang dilakukan penuturnya yang fasih pada masa sebelum atau saat keempat sumber tersebut mulai ada. Masa ini disebut juga masa ihtijaaj atau istisyhaad yang rentang waktunya dibedakan sesuai domisili orang Arab, yaitu mereka yang tinggal di suku Badui dan perkotaan. Masyarakat Arab Badui dianggap sebagai penutur bahasa Arab yang fasih sampai abad ke-4 hijriah, sedangkan kefasihan masyarakat Arab yang tinggal di perkotaan hanya bertahan sampai akhir abad ke-2 hijriah. Adapun kata-kata serapan yang dihasilkan setelah masa tersebut dinamakan al-muwallad. Sedangkan kata-kata serapan secara keseluruhan tanpa memandang waktu

1 Abd al-Rahim dalamal-Jawaliqi, $A l$ Mu'arrab min Al-Kalaam Al-A jami 'ala Huruufi al-Mu jam (Damaskus: Dar al-Qalam, 1990), h. 13.

\footnotetext{
${ }^{2}$ Al-Jawaliqy, Ibid, h. 52.
}

disebut al-dakhiil. ${ }^{3}$

\section{Karakteristik Bahasa Arab}

Menurut Abdul Alim Ibrahim bahasa Arab adalah bahasa orang Arab sekaligus juga merupakan bahasa Islam, $^{4}$ karena bahasa selain bahasa arab tidak dapat diandalkan untuk memberikan kepastian arti yang tersurat dan tersirat dari makna yang terkandung dalam al-Qur'an, maka kaedahkaedah yang diperlukan dalam memahami alqur'an bersendi atas kaedah-kaedah bahasa arab, memahami asas-asasnya, uslubuslubnya, dan mengetahui rasa-rasanya. ${ }^{5}$

Adapun beberapa ciri-ciri khusus bahasa Arab yang dianggap unik dan tidak dimiliki bahasa-bahasa lain di dunia, sebagai berikut: ${ }^{6}$

\section{Aspek bunyi}

Bahasa pada hakekatnya adanya bunyi, yaitu berupa gelombang udara yang keluar dari paru-paru melalui pipa suara dan melintasi organ-organ speech atau alat bunyi. Bahasa Arab, sebagai salah satu rumpun bahasa Semit, memiliki ciri-ciri khusus dalam aspek

3 Muhammad As'ad al-Nadiry, Fiqh allughah:Manaahiluhu wa Masaa'iluhu (Beirut: Maktabah al-'Ashriyyah, 2009), h. 320

${ }^{4}$ Abdul 'Alim Ibrahim, Al Muwajjih al Fanni li Mudarrisii al Lughoh al 'Arabiyyah, (Al-Qahirah:Dar al Ma'arif,1978), 48.

${ }^{5}$ Hasbi Ash-Shiddieqy, Falsafah Hukum Islam, (Jakarta:Bulan Bintang,1975),57

${ }^{6}$ Moh. Matsna, Karakteristik dan Problematika Bahasa Arab, dalam Jurnal Arabia Vol. I Nomor 1/April-September 1998. (Depok: Prodi Arab Fakultas Sastra UI, 1998). hlm. 3-11 
bunyi yang tidak dimiliki bahasa lain, terutama bila dibandingkan dengan bahasa Indonesia atau bahasa-bahasa daerah yang banyak digunakan di seluruh pelosok tanah air Indonesia. Ciri-ciri khusus itu adalah:
a. Vokal panjang dianggap sebagai fonem (أُو ، ،ي ، أَ (أَ)
b. Bunyi tenggorokan ( أصوات الحلق), yaitu ح dan ع
c. Bunyi tebal ( أصوات مطبقة),

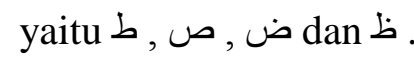
d. Tekanan bunyi dalam kata atau stress (النبر )
e. Bunyi bilabial dental ( شفوى ف (أسنـانى ), yaitu

\section{Aspek Kosa Kata}

Ciri khas kedua yang dimiliki bahasa Arab adalah pola pembentukan kata yang sangat fleksibel, baik melalui derivasi maupun dengan cara infleksi (تصريف إعرابى ) Dengan melalui dua cara pembentukan kata ini, bahasa Arab menjadi sangat kaya sekali dengan عosakata. Misalnya dari akar kata علم , bila dikembangkan dengan cara maka akan menjadi :

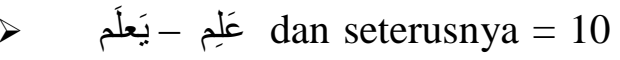

$$
\begin{aligned}
& \text { kata (تعريف اصطلاحي) }
\end{aligned}
$$

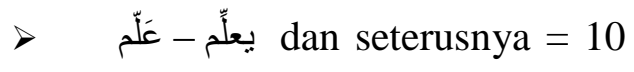

$$
\begin{aligned}
& \text { kata }
\end{aligned}
$$

$$
\begin{aligned}
& \text { dan seterusnya = } 10 \\
& \text { kata } \\
& >\quad \text { idan seterusnya }=10 \\
& \text { kata } \\
& \text { > ت نعالم - dan seterusnya = } 10 \\
& \text { kata } \\
& \text { dan seterusnya }=10 \\
& \text { kata } \\
& \text { Dari masing-masing kata ini }
\end{aligned}
$$

\section{Aspek Kalimat}

\section{a. I'râb}

Bahasa Arab adalah bahasa yang memiliki sistem i'râb terlengkap yang mungkin tidak dimiliki oleh bahasa lain. I'râb adalah perubahan bunyi akhir kata, baik berupa harakat atau pun berupa huruf sesuai dengan jabatan atau kedudukan kata dalam suatu kalimat. I'râb berfungsi untuk membedakan antara jabatan suatu kata dengan kata yang lain yang sekaligus dapat merubah pengertian kalimat tersebut.

Contoh: 
- ما أحسنَ خالداً baiknya si Khalid

- ما أحسنُ خالإٍ artinya apa yang baik pada si Khalid?

- ما أحسنَ خالدٌّ diperbuat baik oleh si Khalid?

b. Jumlah Fi'liyyah dan Jumlah Ismiyyah

Komponen kalimat dalam bahasa apapun pada dasarnya sama, yaitu subyek, predikat dan obyek. Namun, yang berbeda antara satu bahasa dengan bahasa lainnya adalah struktur atau susunan (تركيب) kalimat itu. Pola kalimat sederhana dalam bahasa Arab adalah :

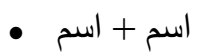

- فعل + اسم

Sementara dalam bahasa Indonesia pola kalimatnya adalah :

- $\mathrm{KB}+\mathrm{KB}$

- $\mathrm{KB}+\mathrm{KK}$

Pola فعل + اسم dalam bahasa Arab sudah dianggap dua kalimat. Dari perbandingan itu, tampak bahwa pola فعل + اسم hanya dimiliki bahasa Arab. Meskipun kadang ada ungkapan bahasa dalam percakapan sehari-hari pola yang sama dengan ini ditemui dalam bahasa Indonesia seperti turun hujan, tetapi ungkapan itu biasanya didahului oleh keterangan waktu umpamanya tadi malam turun hujan.

\section{c. Muthâbaqah (Kesesuaian)}

Ciri yang sangat menonjol dalam susunan kalimat bahasa Arab adalah diharuskannya muthâbaqah atau persesuaian antara beberapa bentuk kalimat. Misalnya harus ada Muthâbaqah antara mubtada' dan khabar dalam hal 'adad (mufrad, mutsannâ dan jama') dan dalam jenis (mudzakkar dan muannats), harus ada Muthâbaqah antara maushûf dan shifat dalam hal 'adad, jenis, i'râb (rafa', nashb, jar), dan nakirah serta ma'rifahnya. Begitu juga harus ada Muthâbaqah antara hâl dan shâhib alhâl dalam 'adad dan jenisnya.

\section{Aspek Huruf}

Ciri yang Nampak dominan pada huruf-huruf bahasa Arab adalah :

a. Bahasa Arab memiliki ragam huruf dalam penempatan susunan kata, yaitu ada huruf yang terpisah, ada bentuk huruf di awal kata, di tengah dan di akhir kata.

b. Setiap satu huruf hanya melambangkan satu bunyi.

c. Cara penulisan berbeda dengan penulisan huruf Latin, yakni dari arah kanan ke kiri.

Disamping itu, ada beberapa huruf yang tidak dibunyikan seperti pada kata-kata أولئك - الزكوة - أنا - لا، أناطالب dan 
sebaliknya, ada beberapa bunyi yang tidak dilambangkan dalam bentuk huruf seperti . تلك - أنتَّ؟ - هذا

\section{Upaya Mempertahankan Gramatika}

\section{Dan Morfologi Bahasa Arab}

\section{Perbedaan Pendapat tentang Arabisasi Kata-kata Asing}

Masing-masing pakar bahasa Arab memiliki standar tersendiri dalam melakukan proses arabisasi kata-kata asing kontemporer. Secara garis besar, sikap mereka terbagi ke dalam tiga kelompok:

\section{a. Kelompok Konservatif}

Mereka yang termasuk kelompok ini memandang bahasa Arab secara mutlak mampu mengatasi problematika arabisasi istilah-istilah baru. Tidak perlu meminjam kata-kata asing seutuhnya. Solusi yang ditawarkan adalah derivasi kata bahasa Arab yang memiliki kesamaan ciri dan arti dengan istilah baru atau menerjemahkannya. Misalnya, kata untuk menunjukkan makna mobil dan frase الصور المتحركة sebagai padanan kata sinematografi.

\section{b. Kelompok Pragmatis}

Kelompok ini memberikan kelonggaran seluas-luasnya untuk meminjam istilah-istilah asing seutuhnya dan menyesuaikannya dengan pola-pola bahasa Arab sehingga bisa dilakukan proses derivasi kata. Argumen ini didasarkan pada beberapa fakta peristiwa di masa lalu, bangsa Arab menyerap kata درهم yang mirip dengan aslinya dan membentuknya menjadi kata baru yang derivatif. Tidak ada halangan untuk melakukan cara seperti ini selama istilah asing tersebut masih bisa disesuaikan dengan huruf dan pola bahasa Arab. Kata تلفون /tilfuun/ terdiri atas huruf-huruf Arab dan sesuai dengan pola فعلون/fi' 'luun/ sehingga dapat dibentuk menjadi akar kata, yaitu تلفن/talfana/ yang inflektif dan derivatif.

\section{c. Kelompok Moderat}

Pandangan kelompok ini menengahi kedua kelompok di atas yang kontradiktif. Langkah pertama yang dilakukan dalam proses pencarian padanan kata bagi istilah-istilah baru adalah berusaha menelusuri kata-kata bahasa Arab asli yang pantas. Namun jika tidak ditemukan padanan kata yang layak, langkah kedua adalah meminjam istilah asing tersebut melalui proses penyesuaian dengan kaidah-kaidah fonologis dan morfologis bahasa Arab.

$$
\text { Metode yang dilakukan }
$$
kelompok moderat lebih dapat diterima karena bersifat objektif dan kondisional. Karena, seandainya kata سيارة هاتف/hatif/, dan مذياع /midzy“, 
/sayyaarah dikatakan kepada orang Arab Badui, ia dapat mengenalnya dengan melihat pola kata-kata tersebut yang menunjukkan alat. Meskipun ia tidak mengetahui maksud sebenarnya dari ketiga kata tersebut, ia dapat mengetahui مذياع sebagai alat penyampai informasi (dzuyu':), sebagai alat komunikasi (هناف), dan سيارة sebagai alat berjalan(sair). Berbeda halnya jika ketiga kata tersebut disampaikan berupa hasil arabisasi راديو ا, رersi kelompok pertama, yaitu تلفون dan أوتومبيل. Orang Arab Baduitersebut tidak akan bisa memahaminya sedikitpun. ${ }^{7}$

Langkah yang diambil kelompok moderat lebih baik dari pada kelompok pertama yang fanatik buta terhadap bahasa Arab. Karena kecintaannya yang berlebihan terhadap bahasa Arab, kelompok pertama telah terbelenggu dari penyesuaian diri dengan kemajuan zaman. Padahal, bahasa Arab sedang hidup di masa yang serba baru. Banyak istilah asing yang belum pernah ditemukan pada masa lalu sehingga mengharuskan adanya usaha Arabisasi. Proses Arabisasi bukanlah sebuah aib bagi sebuah bahasa. Berdasarkan teori sosial, penyerapan

${ }^{7}$ Emil Badi' Ya'qub, Mawsu: 'ah Ùlu:m alLughahal-'Arabiyyah, (Beirut: Dar al-Kutub al'Ilmiyyah, 1971), h. 562-563. bahasa asing merupakan fenomena yang lazim terjadi pada semua bangsa yang saling berinteraksi satu sama lain. Sebuah bahasa tidak akan pernah mampu berdiri sendiri tanpa berkembang maju bersama bahasabahasa lainnya.

Begitu juga pandangan kelompok kedua yang terlalu longgar dalam proses arabisasi. Pengaruh negatif akan timbul dan menyebabkan eksistensi sejati bahasa Arab terancam. Jika semua istilah asing dapat begitu saja diarabisasikan secara utuh, lalu bagaimana nasib bahasa Arab yang sudah kehilangan jati dirinya ini?. Jika langkah ini dibiarkan, bisa jadi suatu saat akan muncul أترمت إلى أوتيل الكوان كالم " ورجعت متنبلا kalm waraja'tu mutanabbilan/ yang semestinya, “ ركبت القطار إلى منامة الز اوية الهادئة 8."ورجعت بالسيارة

\section{Standardisasi Arabisasi Era Kontemporer}

Dalam rangka menertibkan proses Arabisasi di era kontemporer, pusat bahasa Arab di Kairo menetapkan beberapa aturan berikut ini: ${ }^{9}$

a. Pada prinsipnya, arabisasi dibolehkan dalam keadaan darurat dan mesti disesuaikan dengan kaidah bahasa Arab. 
b. Proses derivasi kata-kata nominal hasil arabisasi diperbolehkan, baik disesuaikan dengan pola verba trikonsonantal tak berimbuhan (tsulatsy mujarrad), verba trikonsonantal derivatif (tsulatsy maziid), verba kuadrikonsonantal tak berimbuhan (rubaa'i mujarrad), maupun pola verba kuadrikonsonantal derivatif (rubaa' $i$ maziid).

c. Dalam prakteknya, hasil proses arabisasi berikut derivasinya hanyadigunakan untuk memenuhi kebutuhan ilmiah dan mesti di bawah persetujuanlembaga bahasa Arab. ${ }^{10}$

Emil Badi“ Ya'qub menambahkan, langkah-langkah yang mesti diambil dalam proses Arabisasi harus tertib. Langkah pertama, berusaha menyesuaikan istilah asing dengan lidah orang Arab sehingga mudah diucapkan tanpa terpaku oleh bahasa asal istilah asing tersebut. Langkah kedua, menyesuaikannya dengan pola dalam bahasa Arab yang berlaku. Langkah ketiga, menyertakan istilah asing dengan tulisan latin dalam penulisan hasil Arabisasi. ${ }^{11}$

Seiring berjalannya waktu, kemajuan disegala bidang semakin pesat. Setiap harinya, istilah-istilah baru bermunculan. Bangsa Arab merasa perlu mencari padanan kata bagi istilah-istilah baru tersebut agar tidak ketinggalan zaman. Usaha-usaha untuk mewujudkan hal tersebut gencar dilakukan meskipun masih banyak kekurangan. Masing-masing memiliki standar tersendiri sehingga hasil yang didapatkan berbeda-beda bahkan mengalami degradasi. Oleh karena itu, untuk mengatasi permasalah ini, pusat-pusat bahasa di negaranegara Arab gencar mengadakan seminar dan penelitian. Pusat bahasa Arab di Kairo merupakan lembaga bahasa paling produktif melakukan usaha-usaha progressif menemukan padanan kata bagi istilah-istilah baru dan berhasil menghimpun $70 \%$ istilahistilah kontemporer dalam berbagai bidang. ${ }^{12}$

\section{Urgensi Arabisasi pada Masa Modern}

Proses penyerapan bahasa asing sudah menjadi tabiat semua bahasa. Di dunia ini, tidak ada satu pun bahasa yang terlepas dari proses saling pengaruh mempengaruhi dengan bahasa bangsa lain. Salah satunya bahasa Arab yang telah berumur ribuan tahun namun masih bertahan di tengah kancah kemajuan ilmu pengetahuan dan teknologi. Bahkan, para ahli bahasa, baik dari barat maupun timur tengah, menyatakan keunggulan bahasa Arab atas bahasa-bahasa Semit lainnya. Bahasa Arab terbukti sebagai

\footnotetext{
${ }^{10}$ Ibid.,h. 568-569

${ }^{11}$ Ibid., h. 564
}

${ }^{12}$ Ibid., h. 561 
satu-satunya bahasa Semit yang paling mendekati induk bahasa Semit dan masih tetap bertahan hingga sekarang. ${ }^{13}$

Salah satu bentuk adaptasi bahasa Arabdengan kemajuan zaman adalah penyerapan bahasa asing yang dilakukan sesuaikaidah bahasa Arab yang baik dan benar. Proses arabisasi ini sangat pentingdilakukan mengingat beberapa alasan berikut ini:

a. Proses penyerapan bahasa asing merupakan tabiat semua bahasa di dunia.

b. Memaksakan diri menggunakan kata-kata bahasa Arab klasik dalam proses arabisasi tidak akan mendatangkan solusi yang tepat. Mengingat banyak sekali istilahistilah asing yang dihasilkan melalui proses arabisasi seperti ini tidak mencapai esensi yang dimaksud terutama istilah-istilah ilmu sains, seperti kimia, biologi, dan lain-lain. Saat ini, jumlah istilah-istilah khusus mencapai 1,5 juta kata dengan rata-rata 150 istilah baru per harinya. Diantaranya, 50 ribu istilah ilmu kedokteran.

c. Bahasa-bahasa Eropa memiliki kemampuan membuat istilah-istilah baru dalam setiap penemuanpenemuan penting ilmu pengetahuan dan teknologi. Kompetensi ini tidak dimiliki bahasa Arab mengingat sukarnya mencari kata-kata yang saling memiliki korelasi satu sama lain. Di antara langkah bahasa Arab dalam membentuk istilah-istilah baru adalah tarkiib majzy dan naht(susut). Untuk mencari padanan kata amfibi contohnya, gabungan kata بر/barr/ dan /m/ menjadi برمائي/barm'ii/. Selain itu, metode pembentukan kata seperti ini yang tidak ilmiah, makna yang dihasilkannyapun tidak secara jelas menunjukkan arti yang dimaksud, bahkan cenderung memancing kesalahfahaman. Oleh karena itu, ta 'riib dalam hal ini sangat diutamakan agar dapat lebih jelas dan tepat sasaran. $^{14}$

\section{Usaha-usaha Peningkatan Kualitas bahasa Arab di Era Globalisasi}

Bahasa Arab tidak mungkin terhindar dari proses Arabisasi mengingat besarnya jumlah peningkatan kuantitas istilah-istilah ilmiah setiap harinya. Lembaga-lembaga bahasa Arab telah berupaya mencari padanan kata bagi istilah-istilah baru tersebut dan membukukannya dalam kamus-kamus istilah. Namun, langkah besar ini tidak menyelesaikan masalah secara menyeluruh mengingat istilah-istilah asing telah lebih 
dahulu menyebar di tengah-tengah masyarakat Arab sebelum diproses secara profesional oleh lembaga-lembaga bahasa Arab. Sehingga akhirnya berimplikasi pada dua kemungkinan: kemungkinan pertama, penggunaan dua macam hasil proses arabisasi, sepertikata مذياع dan تلفون dan ر آوتومبيل, هاتف ميوا, سيارة; kemungkinan kedua, penggunaan salah satu hasil proses arabisasi secara massif sehingga memarginalkan kata lainnya, terutama dalam kasus ini, tergerusnya penggunaan padanan kata dari bahasa Arab asli. Tidak mustahil, penggunaan kata هذياع, سيارة akan hilang ditelan masa. Kedua kemungkinan ini menumbuhkan dan memperkuat dugaan atas kelemahan bahasa Arab menjadi bahasa ilmu pengetahuan dan teknologi di era globalisasi yang selalu digembargemborkan oleh para penjajah bangsa Arab.

Untuk mengatasi kemungkinankemungkinan diatas, diperlukan langkahlangkah terorganisir hasil kerja sama semua pihak, baik pemerintah, lembaga pendidikan, lembaga bahasa, media massa, dan rakyat. Berikut ini beberapa solusi yang ditawarkan:

a. Lembaga-lembaga bahasa Arab harus lebih cepat mengkaji istilahistilah ilmiah dan berlomba dengan percepatan penyebarannya di tengah-tengah masyarakat Arab.
Kemudian sesegera mungkin mempublikasikan hasilnya melalui media massa.

b. Menggencarkan penggunaan bahasa Arab dalam berbagai bidang, terutamabidang pendidikan. Saat ini, ada beberapa seruan negatif yang mengancameksistensi bahasa Arab: seruan penggunaan bahasa Arab slang secara resmi danpenggunaan bahasa asing dalam sektor pendidikan secara total, terutamaperguruan tinggi agar tidak tertinggal dari percaturan pemikiran global. Seruan-seruanini merupakan salah satu bentuk penjajahan kebudayaan bangsa asing terhadapbangsa Arab.

Setidaknya, ada tiga dampak positif yang didapatkan saat menjadikan bahasa Arab sebagai bahasa pengantar dalam sektor pendidikan: pertama,memecahkan problematika arabisasi istilah-istilah asing; Kedua, meminimalisir jurang pemisah antara bahasa Arab fushha dan 'aamiyah; dan Ketiga,memudahkan penyampaian materimateri ilmiah. ${ }^{15}$

\section{Kesimpulan}

Arabisasi kata-kata asing dalam istilah Arab dikenal dengan al-ta'tib, secara etimologis, al-ta'rib telah terdefinisikan

\footnotetext{
${ }^{15}$ Ibid., h 565-567
} 
sebagai proses penyerapan bahasa asing ke dalam bahasa Arab.

Aspek-aspek keunikan khusus bahasa Arab yang tidak dimiliki bahasabahasa lain di dunia mencakup aspek bunyi, aspek kosa kata, aspek kalimat, aspek huruf, dan lain-lain.

Ada tiga kelompok pendapat pakar tentang arabisasi kata-kata asing: yaitu kelompok konservatif, kelompok pragmatis, dan kelompok moderat. Pendapat kelompok moderat lebih mewakili semua aspirasi para pakar bahasa Arab.

langkah-langkah yang mesti diambil dalam proses Arabisasi harus tertib. Langkah pertama, berusaha menyesuaikan istilah asing dengan lidah orang Arab sehingga mudah diucapkan tanpa terpaku oleh bahasa asal istilah asing tersebut. Langkah kedua, menyesuaikannya dengan pola dalam bahasa Arab yang berlaku. Langkah ketiga, menyertakan istilah asing dengan tulisan latin dalam penulisan hasil Arabisasi

\section{Daftar Pustaka}

Abd al-Rahim dalamal-Jawaliqi, $A l$ Mu'arrab min Al-Kalaam Al-A'jami 'ala Huruufi al-Mu'jam, Damaskus: Dar al-Qalam, 1990.

Abdul 'Alim Ibrahim, Al Muwajjih al Fanni li Mudarrisii al Lughoh al 'Arabiyyah, Al-Qahirah:Dar al
Ma'arif,1978.

Emil Badi' Ya'qub, Mawsu:'ah Ùlu:m alLughahal-'Arabiyyah, Beirut: Dar alKutub al-'Ilmiyyah, 1971.

Hasbi Ash-Shiddieqy, Falsafah Hukum Islam, Jakarta:Bulan Bintang,1975.

Moh. Matsna, Karakteristik dan Problematika Bahasa Arab, dalam Jurnal Arabia Vol. I Nomor 1/April-September 1998. Depok: Prodi Arab Fakultas Sastra UI, 1998.

Muhammad As'ad al-Nadiry, Figh allughah:Manaahiluhu wa Masaa'iluhu Beirut: Maktabah al-'Ashriyyah, 2009. 